\title{
Smell and Taste Disturbance in COVID-19 Patients: A Prospective Multicenteric Review
}

\author{
Subash Bhatta ${ }^{1}$ - Dibya Sharma ${ }^{1} \cdot$ Santosh Sharma $^{2} \cdot$ Leison Maharjan $^{3} \cdot$ Sushma Bhattachan $^{4}$. \\ Mukesh Kumar Shah $^{5} \cdot$ Aditya Singhal $^{6} \cdot$ Asheesh Dora Ghanpur $^{7} \cdot$ Dushyanth Ganesuni $^{8}$. \\ Shraddha Jayant Saindani'
}

Received: 19 March 2021/Accepted: 24 May 2021/Published online: 28 May 2021

(C) Association of Otolaryngologists of India 2021

\begin{abstract}
To study the incidence of the smell and taste disturbance in the COVID-19 patients and a follow up at 4 months to observe for the duration of resolution of these symptoms. This is a multicentric prospective study carried out in 3 different countries, from April, 2020 to January, 2021. The COVID-19 positive patients, aged between 15 and 60 years, were inquired about the presence of any smell or taste related symptoms. The same patients were followed up with the telephonic interview after 2 months and then after 4 months, respectively. The duration of resolution of the smell and taste disturbance symptoms was noted. Total of 188 COVID-19 positive patients, average age $33.1 \pm 1.7$ years, $54.2 \%$ males and $45.8 \%$ female were included in the study. The smell disturbance was present in $60.6 \%$ (hyposmia $36.1 \%$, anosmia $20.2 \%$, and parosmia
\end{abstract}

This manuscript has been read and approved by all the authors and the requirements for authorship have been met. Each author approves that the manuscript represents original work.

Subash Bhatta

2042subase@gmail.com

Indira Gandhi Memorial Hospital, Male', Maldives

2 Devdaha Medical College, Butwal, Nepal

3 Patan Academy of Health Sciences, Patan, Nepal

4 Hospital for Advanced Medicine and Surgery, Kathmandu, Nepal

5 National Medical College, Birgunj, Nepal

6 Rajshree Medical Research Institute, Bareily, India

7 Osmania Medical College, Hyderabad, India

8 Continental Hospital and Research Center, Hyderabad, India

9 Deenanath Mangeshkar Hospital and Research Center, Pune, India
$4.2 \%$ ) and taste disturbance in $28.7 \%$ of patients (hypogeusia $20.2 \%$, ageusia $6.9 \%$, and parageusia $1.6 \%$ ). There was improvement of anosmia by 97.4 , hyposmia by $95.6 \%$, parosmia by $100 \%$, ageusia by $100 \%$, hypogeusia $94.8 \%$, and parageusia by $66.7 \%$, at 4 months follow up. The present study concludes that the smell and taste disturbances are one of the main early presenting features of the COVID-19 infection. The temporary effect of the COVID-19 infection on the olfactory and gustatory pathway was also highlighted with more than $95 \%$ patients improving at 4 months of follow up.

Keywords COVID-19 infection - Smell disturbance · Taste disturbance $\cdot$ Prospective

\section{Introduction}

The Coronavirus disease 2019 (COVID-19) is caused by severe acute respiratory syndrome coronavirus 2 (SARSCoV-2) [1, 2]. It was declared pandemic by WHO on March 11, 2020 [3]. The COVID-19 targets those cells of the body, which expresses angiotensin-converting enzyme 2 (ACE-2) receptors such as; stratified epithelial cells, type II alveolar cells, absorptive enterocytes from ileum and colon, glial cells and neurons, myocardial cells, bladder urothelial cells, proximal tubule cells of the kidney, oral epithelial cells, and nasal epithelial cells [4-8]. As a result, the COVID-19 infection has very diverse presentation such as, fever, sore throat, cough, breathing difficulty, olfactory and gustatory disturbances, headache, diarrhea, myalgia, rhinorrhea, nasal obstruction, fatigue, post nasal drip, and expectoration [9-15].

The smell and taste disorders have long been studied in association with various viral upper respiratory tract 
infections such as; influenza and parainfluenza virus, respiratory syncytial virus, rhinovirus, and other endemic coronavirus [16, 17]. The highest concentration of the ACE-2 has been described in the epithelium of the nasal and oral mucosa [6, 7]. It has been proposed in the recent literature that the COVID-19 virus invades the central nervous system epithelium via the olfactory neuroepithelium, and subsequently spreads to the olfactory bulb utilizing the neuron-to-neuron propagation [18, 19]. This has resulted in the olfactory and gustatory disturbances in the patients with COVID-19 infection.

The chemo sensitive dysfunctions such as; the anosmia, hyposmia, parosmia, ageusia, hypogeusia, and par ageusia, constitute one of the most frequent symptoms in the early stages of the COVID-19 infection [20]. Various studies have elaborated the smell and taste dysfunction during the COVID-19 infection [17, 21-26]. The present study is a first multicentric research performed in 3 different countries to evaluate the incidence of smell and taste disturbance with the duration of their resolution, in the patients with COVID-19 infection, with 4 months follow up. Vaira et al. [20] have performed the similar study in 3 different institutes of Italy with a 60 day follow up.

\section{Method and materials}

This was the prospective study conducted from April 2020 to January 2021. It was simultaneously carried out in 10 different institutes namely; Indira Gandhi memorial hospital (IGMH) (Male', Maldives), Patan academy of health sciences (PAHS) (Patan, Nepal), Deenanath Mangeshkar hospital and research center (DMH) (Pune, India), Hospital for advanced medicine and surgery (HAMS) (Kathmandu, Nepal), Devdaha Medical college (DMC) (Butwal, Nepal), National Medical college (NMC) (Birgunj, Nepal), Osmania Medical college (OMC) (Hyderabad, India), Continental hospital and research center (CHRC) (Hyderabad, India) and Rajshree Medical Research Institute (RMRI) (Bareily, India). The ethical approval for the study was granted from the institutional ethical committee of the respective hospitals.

The patients found positive for COVID-19 infection with the reverse transcriptase polymerase chain reaction (RT PCR) were included in the study. Patients of all genders and age between 14 and 60 years, and without any previous history of the smell and taste disorder, were included in the study. The patients with any previously known nasal pathology or any previously known allergies were excluded from the study. Patients with previous history of trauma, surgery or radiotherapy in the nasal cavity or oral cavity, along with the patients with any known neurological or psychiatric disease, were also excluded from the study. The patients were described in the brief about the research article in their respective local languages. The participation into the study was only considered after taking the consent from the patients. The participants were assured regarding the confidentiality of the information provided.

The detailed history was obtained for all the COVID-19 positive patients included in the study. The demographic profile, age, gender, and the presence or absence of smell and taste disturbance were elaborated in detail. The disturbance of smell or taste was elaborated under four headings: normal smell or taste, parosmia or parageusia, hyposmia or hypogeusia and anosmia or ageusia. The normal smell or taste was defined as the no disturbance in the smell or taste, parosmia or parageusia was defined as the alteration of smell or taste sensation for the previously known substances, hyposmia or hypogeusia was defined as the decreased sensation of smell or taste, and anosmia or ageusia was defined as total absence of smell or taste, respectively. The patients with smell and taste disturbance symptoms were followed up after 2 months and then after 4 months with the telephonic interview. During the follow up, the patients were inquired about resolution of the smell and taste symptoms. The resolution was defined as the complete absence of the symptoms previously present. The decrease in symptom intensity was not considered as the resolution of the symptoms. The COVID-19 patients who were not having any smell or taste disturbances initially were also inquired, through telephonic interview, at 2 months follow up for the recent onset of smell and taste disturbance, if any. The patient who could not be reached during the follow up, were excluded from the study.

\section{Results}

A total of 188 COVID-19 positive patients were included in the study; IGMH (21), PAHS (23), HAMS (17), NMC (23), DMC (12), OMC (24), DMH (27), CHRC (18) and RMRI (23). The average age of the patients was $33.1 \pm 1.7$ years (21-43 years). There were 102/188 (54.2\%) males and 86/188 (45.8\%) female patients. The presenting features of the patients at the initial presentation is as shown in the Fig. 1. The duration of the smell and taste disturbance symptoms onset before the COVID-19 RT PCR positive test is as shown in Fig. 2.

The cough and sore throat were the most common clinical manifestations. The number of patients with smell and taste disturbance initially, and then after 2 months and 4 months are as shown in the Fig. 3.

There was improvement of anosmia by $81.6 \%$ after 2 months and by 97.4 after 4 months. Similarly, hyposmia improved by $63.6 \%$ and $95.6 \%$, parosmia by $100 \%$ and 
Fig. 1 Presenting features of COVID-19 positive patients

Fig. 2 Duration of smell and taste disturbance symptoms onset before the positive COVID-19 RT PCR test, along with the SD

Fig. 3 COVID-19 positive patients with smell and taste disturbance initially, after 2 months and after 4 months follow up
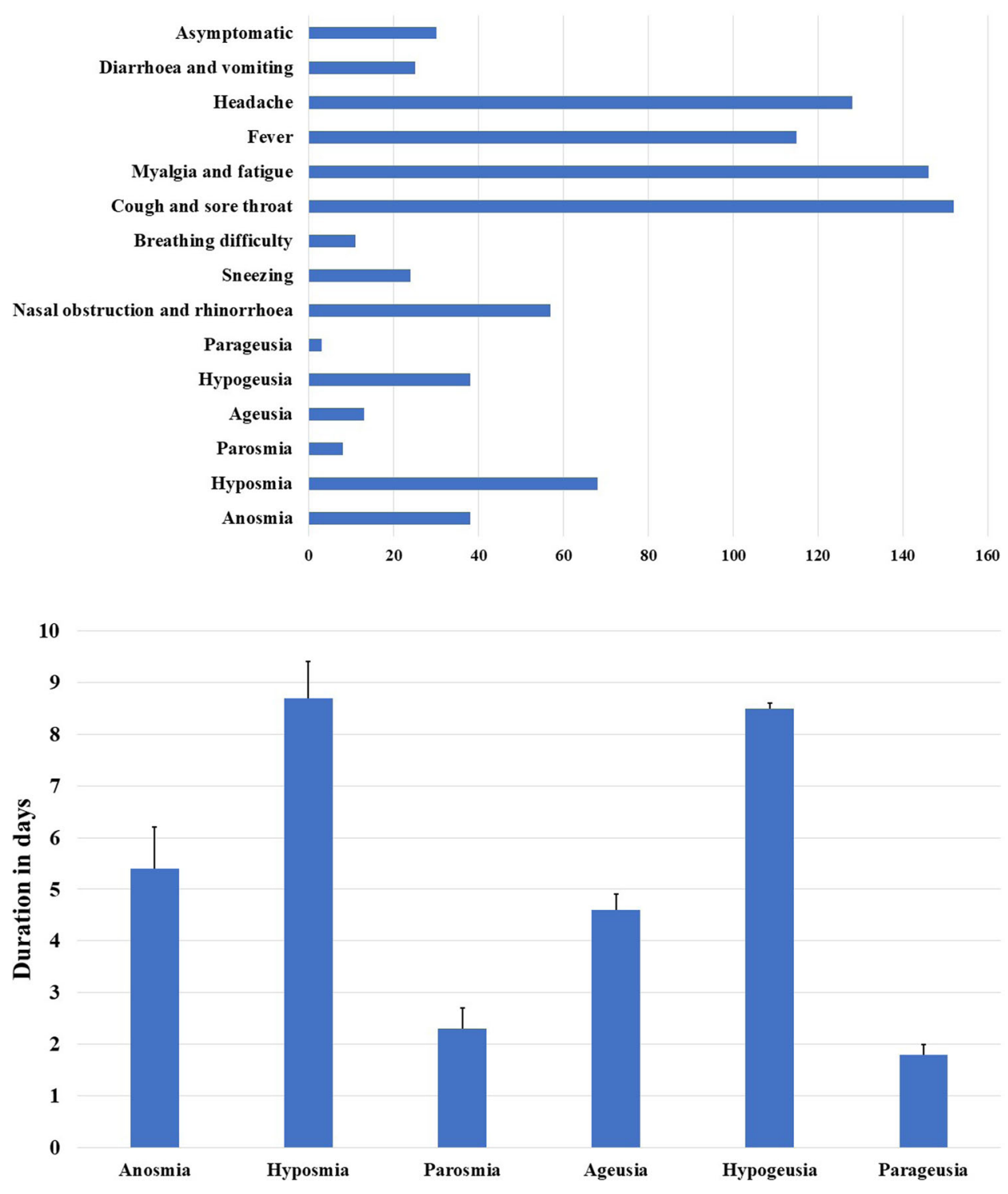

40

35

30

25

20

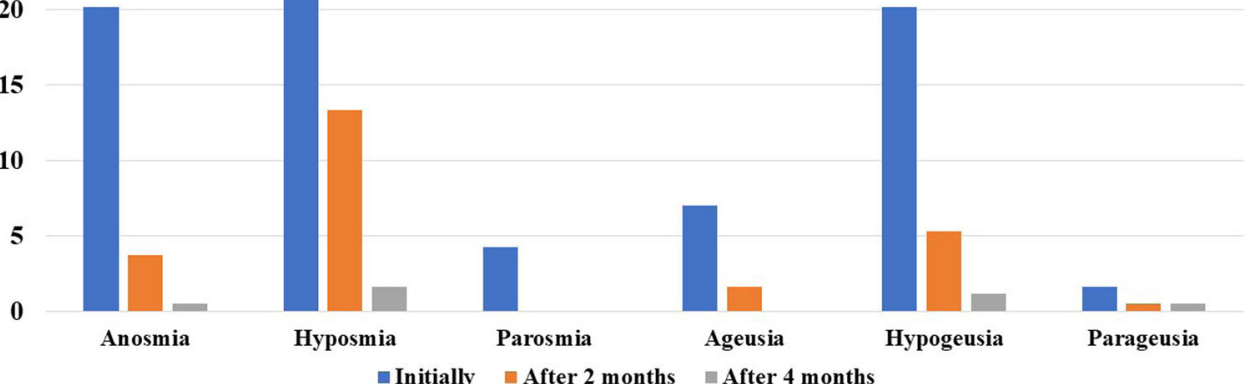


$100 \%$, ageusia by $77 \%$ and $100 \%$, hypogeusia by $73.7 \%$ and $94.8 \%$, and parageusia by 66.7 and $66.7 \%$, after 2 months and 4 months follow up, respectively. The 30 asymptomatic patients were also called after 2 months to check for emergence of any new symptoms. There were no new onset smell and taste disturbance symptoms in the asymptomatic patients. The asymptomatic patients were not called for the 4 months follow up.

\section{Discussion}

This study evaluates the COVID-19 positive patients for the presence of smell and taste disturbance and also follows them at 4 months to look for the resolution of these symptoms. The patients were inquired about the presence and absence of the smell and taste disturbance subjectively during the history taking procedure. This study did not incorporate any objective or psychophysical methods for evaluation of smell and test as described by some other studies in the literature [20, 27-29]. The mandate for adopting strict safety protocols for COVID-19 was the reason behind not being able to evaluate the smell and taste disturbance by any other methods. Similarly, the lower inclusion criteria for age was set at 15 years in order to avoid the bias from the subjective evaluation of the smell and taste with the younger childhood age group. The upper age limit was set at 60 years with an intention to avoid the age-related smell and taste disturbance, as described by studies in the literature [30-32]. Various other studies have also selected a similar age demographic for lower age [20, 33].

The study showed smell disturbance present in $60.6 \%$ of patients, (hyposmia 36.1\%, anosmia 20.2\%, and parosmia $4.2 \%$ ) and taste disturbance in $28.7 \%$ of patients, (hypogeusia $20.2 \%$, ageusia $6.9 \%$, and parageusia $1.6 \%$ ). There were no patients with isolated taste disturbance symptoms, however, $52.6 \%$ of the patients with smell disturbance had no taste disturbance. These findings can be inferred to the mechanism of loss of the taste caused by the loss of smell due to the retro nasal olfaction as mentioned by studies in the literature [34, 35]. In contrast to these findings, there are studies suggesting the etiology behind the loss of taste, due to the bonding between COVID-19 and receptor of sialic acid, resulting in degradation of taste particles [36, 37]. There was no study found in the literature that has described the loss of smell and taste sensation in COVID-19 infection separately with the underlying pathophysiology behind it.

This study further classifies the loss of smell and taste sensation into hyposmia, anosmia, and parosmia and hypogeusia, ageusia and par ageusia, respectively. These all symptoms were defined previously and then clearly described to the patients, so that the patients would be able to exactly figure out the problem in smell or taste. As this was a subjective evaluation, the preciseness during the history taking was felt to be essential. The loss of smell and taste was generally very vague explanation from the patients, and it did not include the parosmia or parageusia. Since there were significant number of COVID-19 patients with complain of parosmia or parageusia, these were also evaluated separately.

The study performed by Cazzola et al. [33] have demonstrated isolated smell dysfunction in $65.7 \%$, isolated taste dysfunction in $25.4 \%$ (in contrast to the present study, where there were no patients with isolated taste dysfunction) and combined smell and taste dysfunction in $8.5 \%$. They have not described pathophysiology behind the higher frequency of isolated smell and taste dysfunction. The present study was performed amongst the COVID-19 positive patients only, in contrast Izquierdo-Domínguez et al. [26] selected the control group also in their study in addition to the COVID-19 patients. The control group consisted of the patients with symptoms of flu but having 2 consecutively negative RT PCR test for COVID-19 infection. They demonstrated loss of taste in $53.7 \%$ with exclusive loss of taste in $5 \%$ and loss of smell in $52.2 \%$ with exclusive loss of smell in $6.5 \%$ of the COVID-19 patients, the incidence of smell and taste disturbance as demonstrated by them was double in the COVID- 19 patients in comparison to the control group. Similarly, Lechian [21] demonstrated olfactory disturbance in $85.6 \%$ (anosmia $7.6 \%$, hyposmia $20.4 \%$, phantosmia $12.6 \%$ and parosmia $32.4 \%$ ) and taste disturbance in $88.8 \%$. Valentina Parma et al. [17] showed smell disturbance in $90.18 \%$ and taste disturbance in $91.44 \%$ with chemesthesis in $84.96 \%$, the parosmia was present in $7.77 \%$ and phantosmia in 7.8\%. Unlike the present study, Valentina Parma et al. [17] further sub divided loss of taste according to different types of taste sensation (sweet, salt, sour and bitter), with $11 \%$ having loss of single taste sensation and $48 \%$ having loss of 2 or more taste sensation. Subash Bhatta et al. [15] in their study of 600 patients with COVID-19 demonstrated smell disturbance in $63.6 \%$ and taste disturbance in $63.5 \%$ of the patients.

The present study demonstrated improvement in anosmia by $97.4 \%$, hyposmia by $95.6 \%$, parosmia by $100 \%$, ageusia by $100 \%$, hypogeusia by $94.8 \%$ and parageusia by $66.7 \%$ at 4 months follow up respectively. Vaira et al.[38] reported the presence of mild hyposmia and hypogeusia in $15.2 \%$ and $3.6 \%$ cases, respectively at the end of 60 days follow up. Izquierdo-Domínguez A et al. [26] reported recovery of smell and taste disturbance in $45.5 \%$ of COVID-19 patients, with $90.6 \%$ patients recovering in less than 2 weeks and $9.4 \%$ patients requiring more than 2 weeks for recovery. Yonghyun Lee et al. [39] 
demonstrated the median time for recovery of anosmia and ageusia to be 7 days, similarly mean time of improvement of the anosmia was shown to be 7.2 days, by Rachel Kaye et al. [40]. Hence, it can be inferred that the smell and taste disturbance tend to recover with time in the patients with COVID-19 infection. However, there still is lack of firm evidence suggesting the exact natural course of improvement or persistence of these symptoms. The improvement in the olfactory and gustatory symptoms over the period of time in the patients following COVID-19 infection suggests some transient inflammatory response of the virus over the nasal and oral epithelial cells and the sensory receptors $[38,41]$. The occurrence of the permanent damage to the olfactory and gustatory pathway however seems unlikely due to the COVID-19 infection [2, 5, 7, 16, 29]. The variation in the time duration and frequency of the olfactory and gustatory symptoms resolution for COVID19 positive patients could not be explained.

There were no patients who complained of late onset smell and taste disturbance as demonstrated by the present study. Similarly, Vaira et al. [20], demonstrated no deterioration in smell and taste scores with in the initial 10 days after symptoms onset. However, they did not inquire the asymptomatic COVID-19 positive patients for emergence of new olfactory and gustatory symptoms. The disturbance in taste and smell has been shown by various study as the early manifestations of the COVID-19 infection, and the evidence of these symptoms occurring late in the course of infection is very scarce $[42,43]$.

The present study, being a unique study of its kind, had few limitations such as a smaller number of sample size and the telephonic interview for follow up of the patients. The lack of the firm evidence on the smell and taste disturbance during the COVID-19 infection demands more future research regarding the smell and taste disturbance in COVID-19 infection. The present study recommends a research with larger sample size and with increased duration of in-person follow up for the better understanding of the subject matter.

\section{Conclusion}

It can be concluded from the present study that the olfactory and gustatory disturbance are one of the main early presentations of the COVID-19 infection. The temporary affect of the COVID-19 infection on the olfactory and gustatory pathway was also highlighted with more than 95\% patients improving at the 4 months of follow up. The presence of olfactory and gustatory symptoms in this time of pandemic must be evaluated precisely, with the suspicion of COVID-19 infection. The smaller sample size and telephonic follow up interview were felt to be the limitation of the study, hence a larger sample sized research with in person follow up has been suggested.

Acknowledgements This research was fully supported by the ENT department and the research department of the Indira Gandhi memorial hospital (IGMH) (Male', Maldives), Patan academy of health sciences (PAHS) (Patan, Nepal), Hospital for advanced medicine and surgery (HAMS) (Kathmandu, Nepal), Devdaha Medical college (DMC) (Butwal, Nepal), National Medical college (NMC) (Birgunj, Nepal), Osmania Medical college (OMC) (Hyderabad, India), Continental hospital and research center (CHRC) (Hyderabad, India), Deenanath Mangeshkar hospital and research center (DMH) and Rajshree Medical Research Institute (RMRI) (Bareily, India). We would like to extend our heartful thanks to all our colleagues from ENT Department of these institutes who provided insight and expertise that greatly assisted the research. Few names to mention of special thanks, we would like to thank Dr Pallavi Sinha, head of research department (OMC), Dr Gayatri Yadav, head of research department (NMC), Dr Nina Pathak, head of research department (PAHS), Ahmed Khan, Ravi Ojha and Shweta Shrestha, research assistant, research Department of IGMH, DMC, and HAMS respectively, for their immense assistance in the biostatistics, language correction and technical issues.

\section{Declarations}

Conflict of interest There was no conflict of interest.

\section{References}

1. Wiersinga WJ, Rhodes A, Cheng AC, Peacock SJ, Prescott HC (2020) Pathophysiology, transmission, diagnosis, and treatment of Coronavirus Disease 2019 (COVID-19): a review. JAMA J Am Med Assoc 324:782-793. https://doi.org/10.1001/jama.2020.12839

2. Yuki K, Fujiogi M, Koutsogiannaki S (2020) COVID-19 pathophysiology: a review. Clin Immunol 215:108427. https://doi.org/10.1016/j.clim.2020.108427

3. Cucinotta D, Vanelli M (2020) WHO declares COVID-19 a pandemic. Acta Biomed 91:157-160. https://doi.org/10.23750/abm.v91i1.9397.

4. Zou X, Chen K, Zou J, Han P, Hao J, Han Z (2020) Single-cell RNA-seq data analysis on the receptor ACE2 expression reveals the potential risk of different human organs vulnerable to 2019-nCoV infection. Front Med 14:185-192. https://doi.org/10.1007/s11684-020-0754-0

5. Baig AM, Khaleeq A, Ali U, Syeda H (2020) Evidence of the COVID-19 virus targeting the CNS: tissue distribution, host-virus interaction, and proposed neurotropic mechanisms. ACS Chem Neurosci https://doi.org/10.1021/acschemneuro.0c00122

11:995-998.

6. Sungnak W, Huang N, Bécavin C, Berg M, Queen R, Litvinukova $\mathrm{M}$ et al (2020) SARS-CoV-2 entry factors are highly expressed in nasal epithelial cells together with innate immune $\begin{array}{llll}\text { genes. } & \text { Nat } & \end{array}$ https://doi.org/10.1038/s41591-020-0868-6

7. Xu H, Zhong L, Deng J, Peng J, Dan H, Zeng X et al (2020) High expression of ACE2 receptor of 2019-nCoV on the epithelial cells of oral mucosa. Int $\mathrm{J}$ Oral Sci 12:1-5. https://doi.org/10.1038/s41368-020-0074-x

8. Zhang H, Kang Z, Gong H, Xu D, Wang J, Li Z et al (2020) The digestive system is a potential route of 2019-nCov infection: a bioinformatics analysis based on single-cell transcriptomes. 
BioRxiv

https://doi.org/10.1101/2020.01.30.927806.

2020:2020.01.30.927806.

9. Mizumoto K, Kagaya K, Zarebski A, Chowell G (2020) Estimating the asymptomatic proportion of coronavirus disease 2019 (COVID-19) cases on board the Diamond Princess cruise ship, Yokohama, Japan, 2020. Eurosurveillance 25:2000180. https://doi.org/10.2807/1560-7917.ES.2020.25.10.2000180

10. Liu K, Chen Y, Lin R, Han K (2020) Clinical features of COVID19 in elderly patients: a comparison with young and middle-aged patients. $\quad \mathrm{J}$ Infect 80:e14-e18. https://doi.org/10.1016/j.jinf.2020.03.005

11. Guan W, Ni Z, Hu Y, Liang W, Ou C, He J, et al (2020) Clinical characteristics of 2019 novel coronavirus infection in China. N Engl J Med. https://doi.org/10.1101/2020.02.06.20020974.

12. Liu K, Fang YY, Deng Y, Liu W, Wang MF, Ma JP et al (2020) Clinical characteristics of novel coronavirus cases in tertiary hospitals in Hubei Province. Chin Med J (Engl) 133:1025-1031. https://doi.org/10.1097/CM9.0000000000000744

13. Fang Z, 3\# Y, Wu K, Lai K, Sun X, Zhong $\mathrm{N}$ et al. Clinical Characteristics of 2019 Coronavirus Pneumonia (COVID-19): an updated systematic review n.d. https://doi.org/10.1101/2020.03.07.20032573.

14. Hassan SA, Sheikh FN, Jamal S, Ezeh JK, Akhtar A (2020) Coronavirus (COVID-19): a review of clinical features, diagnosis, and treatment. https://doi.org/10.7759/cureus.7355.

15. Bhatta S, Gandhi S, Saindani SJ, Ganesuni D, Ghanpur AD, Otorhinolaryngological Manifestations of Coronavirus Disease (2019) a prospective review of 600 patients. J Laryngol Otol 2021:1-15. https://doi.org/10.1017/S0022215121000220

16. Soler ZM, Patel ZM, Turner JH, Holbrook EH (2020) A primer on viral-associated olfactory loss in the era of COVID-19. Int Forum Allergy Rhinol 10:814-820. https://doi.org/10.1002/alr.22578

17. Parma V, Ohla K, Veldhuizen MG, Niv MY, Kelly CE, Bakke AJ et al (2020) More than smell-COVID-19 is associated with severe impairment of smell, taste, and chemesthesis. Chem Senses 45:609-622. https://doi.org/10.1093/chemse/bjaa041

18. Dubé M, Le Coupanec A, Wong AHM, Rini JM, Desforges M, Talbot PJ (2018) Axonal transport enables neuron-to-neuron propagation of Human Coronavirus OC43. J Virol, 92. https://doi.org/10.1128/jvi.00404-18.

19. Desforges M, Le Coupanec A, Dubeau P, Bourgouin A, Lajoie L, Dubé $\mathrm{M}$ et al (2019) Human Coronaviruses and other respiratory viruses: underestimated opportunistic pathogens of the central nervous system? Viruses 12:14. https://doi.org/10.3390/v12010014

20. Vaira LA, Hopkins C, Petrocelli M, Lechien JR, Chiesa-Estomba CM, Salzano G et al (2020) Smell and taste recovery in coronavirus disease 2019 patients: a 60-day objective and prospective $\begin{array}{llll}\text { study. J } & \text { Laryngol Otol }\end{array}$ https://doi.org/10.1017/S0022215120001826

21. Lechien JR, Hopkins C, Saussez S (2020) Sniffing out the evidence; it's now time for public health bodies recognize the link between COVID-19 and smell and taste disturbance. Rhinology 58:1-2. https://doi.org/10.4193/Rhin20.159

22. Coelho DH, Kons ZA, Costanzo RM, Reiter ER (2020) Subjective changes in smell and taste during the COVID-19 pandemic: a National Survey-Preliminary Results. Otolaryngol Head Neck Surg (United States) 163:302-306. https://doi.org/10.1177/0194599820929957

23. Moein ST, Hashemian SMR, Mansourafshar B, Khorram-Tousi A, Tabarsi P, Doty RL (2020) Smell dysfunction: a biomarker for COVID-19. Int Forum Allergy Rhinol 10:944-950. https://doi.org/10.1002/alr.22587
24. Kerr C, Hughes G, McKenna L, Bergin C (2020) Prevalence of smell and taste dysfunction in a cohort of CoVID19 outpatients managed through remote consultation from a large urban teaching hospital in Dublin. Ireland Infect Prev Pract 2:100076. https://doi.org/10.1016/j.infpip.2020.100076

25. Roland LT, Gurrola JG, Loftus PA, Cheung SW, Chang JL (2020) Smell and taste symptom-based predictive model for COVID-19 diagnosis. Int Forum Allergy Rhinol 10:832-838. https://doi.org/10.1002/alr.22602

26. Izquierdo-Domínguez A, Rojas-Lechuga MJ, Chiesa-Estomba C, Calvo-Henríquez C, Ninchritz-Becerra E, Soriano-Reixach M et al (2020) Smell and taste dysfunction in covid-19 is associated with younger age in ambulatory settings: a multicenter crosssectional study. J Investig Allergol Clin Immunol 30:346-357. https://doi.org/10.18176/jiaci.0595.

27. Mazzatenta A, Neri G, D'Ardes D, De Luca C, Marinari S, Porreca E et al (2020) Smell and taste in severe CoViD-19: selfreported vs. testing. Front Med 7:589409. https://doi.org/10.3389/fmed.2020.589409.

28. Sayin İ, Yaşar KK, Yazici ZM (2020) Taste and smell impairment in COVID-19: An AAO-HNS anosmia reporting tool-based comparative study. Otolaryngol Head Neck Surg (United States) 163:473-479. https://doi.org/10.1177/0194599820931820

29. Bhattacharyya N, Kepnes LJ (2015) Contemporary assessment of the prevalence of smell and taste problems in adults. Laryngoscope 125:1102-1106. https://doi.org/10.1002/lary.24999

30. Hoffman HJ, Ishii EK, Macturk RH (1998) Age-related changes in the prevalence of smell/taste problems among the United States Adult Population: results of the 1994 disability supplement to the National Health Interview Survey (NHIS). Ann N Y Acad Sci https://doi.org/10.1111/j.1749-6632.1998.tb10650.x

31. Schiffman SS (1997) Taste and smell losses in normal aging and disease. JAMA J Am Med Assoc 278:1357. https://doi.org/10.1001/jama.1997.03550160077042

32. Lafreniere D, Mann N (2009) Anosmia: loss of smell in the elderly. Otolaryngol Clin North Am 42:123-131. https://doi.org/10.1016/j.otc.2008.09.001

33. Cazzolla AP, Lovero R, Lo Muzio L, Testa NF, Schirinzi A, Palmieri G et al (2020) Taste and smell disorders in COVID-19 patients: role of interleukin-6. ACS Chem Neurosci 11:2774-2781. https://doi.org/10.1021/acschemneuro.0c00447

34. Prescott J (2011) Multimodal chemosensory interactions and perception of flavor. Neural bases multisensory process. CRC Press, Boca Raton, pp 703-716. https://doi.org/10.1201/b11092-45.

35. Deems DA, Doty RL, Settle RG, Moore-Gillon V, Shaman P, Mester AF et al (1991) Smell and taste disorders, a study of 750 patients From the University of Pennsylvania Smell and Taste Center. Arch Otolaryngol Neck Surg 117:519-528. https://doi.org/10.1001/archotol.1991.01870170065015

36. Witt M, Miller IJ (1992) Comparative lectin histochemistry on taste buds in foliate, circumvallate and fungiform papillae of the rabbit tongue. Histochemistry 98:173-182. https://doi.org/10.1007/BF00315876

37. Pushpass R-AG, Pellicciotta N, Kelly C, Proctor G, Carpenter GH (2019) Reduced salivary mucin binding and glycosylation in older adults influences taste in an in vitro cell model. Nutrients 11:2280. https://doi.org/10.3390/nu11102280.

38. Vaira LA, Salzano G, Fois AG, Piombino P, De Riu G (2020) Potential pathogenesis of ageusia and anosmia in COVID-19 patients. Int Forum Allergy Rhinol 10:1103-1104. https://doi.org/10.1002/alr.22593

39. Lee Y, Min P, Lee S, Kim SW (2020) Prevalence and duration of acute loss of smell or taste in COVID-19 patients. J Korean Med Sci, 35. https://doi.org/10.3346/JKMS.2020.35.E174. 
40. Kaye R, Chang CWD, Kazahaya K, Brereton J, Denneny JC (2020) COVID-19 Anosmia reporting tool: initial findings. Otolaryngol Head Neck Surg (United States) 163:132-134. https://doi.org/10.1177/0194599820922992

41. Vaira LA, Deiana G, Salzano FA (2020) Functional endoscopic surgery after facial trauma view project Chemosensitive dysfunctions in COVID-19 patients View project 2020. https://doi.org/10.1002/lary.28837.

42. Hopkins C, Surda P, Whitehead E, Nirmal Kumar B. Early recovery following new onset anosmia during the COVID-19 pandemic-an observational cohort study n.d. https://doi.org/10.1186/s40463-020-00423-8.

43. Pierron D, Pereda-Loth V, Mantel M, Moranges M, Bignon E, Alva $\mathrm{O}$ et al (2020) Smell and taste changes are early indicators of the COVID-19 pandemic and political decision effectiveness. Nat Commun

$11: 1-8$.

https://doi.org/10.1038/s41467-020-18963-y

Publisher's Note Springer Nature remains neutral with regard to jurisdictional claims in published maps and institutional affiliations. 